\title{
Fracture properties of green wood formed within the forks of hazel (Corylus avellana $\mathrm{L}$.
}

\author{
Seray Özden ${ }^{1,4} \cdot$ Duncan Slater $^{2} \cdot$ Roland Ennos $^{3}$
}

Received: 25 March 2016 / Accepted: 23 December 2016 / Published online: 3 February 2017

(C) The Author(s) 2017. This article is published with open access at Springerlink.com

\begin{abstract}
Key message Central apex of bifurcations has higher specific fracture energy in TR fracture system than that of four sampling locations. This could be due to higher density and interlocked grain formation.

Abstract Forks are one of the important biomechanical structures in trees because of their potential vulnerability to splitting. Many researchers have investigated the strength and stiffness properties of tree forks, but very little is known about the toughening mechanism within tree forks. In this study, the specific fracture energy $\left(G_{\mathrm{f}}, \mathrm{Jm}^{-2}\right)$ of forks of hazel (Corylus avellana L.) was investigated in the RT (Radial-Tangential) and TR (Tangential-Radial) fracture systems using double-edge-notched tensile tests. Sample $G_{\mathrm{f}}$ values were measured at between the central apex of bifurcations, at the side apices of bifurcations, in the parent stems and in the two branches of forks. The fracture surfaces were analysed by Scanning Electron
\end{abstract}

Communicated by T. Speck.

Seray Özden

serayozden@gmail.com

Duncan Slater

dslater@myerscough.ac.uk

Roland Ennos

R.Ennos@hull.ac.uk

1 Faculty of Life Sciences, University of Manchester, Manchester M13 9PT, UK

2 Myerscough College, St. Michael's Road, Bilsborrow, Preston, Lancashire PR3 ORY, UK

3 School of Biological, Biomedical and Environmental Sciences, University of Hull, Hull HU6 7RX, UK

4 Faculty of Forestry, Kastamonu University, Kastamonu, Turkey
Microscopy (SEM), and the wood density was determined. $G_{\mathrm{f}}$ was found to be considerably greater at the central apex of a bifurcation than in other sampling locations. Surprisingly, $G_{\mathrm{f}}$ of TR was greater than $\mathrm{G}_{\mathrm{f}}$ of RT at the central apex, while the other four locations showed greater $G_{\mathrm{f}}$ values in their RT fracture systems. The density of the central apex of bifurcations was found to be around $22 \%$ greater than elsewhere. In addition, it was shown that there was a more tortuous and interlocked wood grain formation at the central apex of bifurcations. The combination of higher density and tortuous grain structure provides reinforcement at the central apex.

Keywords Tree fork - Bifurcation - Wood toughness . Specific fracture energy $\cdot$ Interlocked wood grain

\section{Introduction}

Trees have extraordinary biomechanical structures; although these large organisms are mainly exposed to both gravity and wind loads over their long life; they are able to provide long-term mechanical stability for survivorship. Gravity or gravitational force is a permanent applied force that pulls the aboveground mass of the tree, so producing loads from tree's own weight (self-weight) (Smiley et al. Tree Risk Assessment). Wind is the most continuous dynamic and largest load in tree which can cause a tree to fall (James 2003). However, a tree can withstand both its self-weight and wind forces by its woody skeleton, which has excellent mechanical properties, being stiff, strong, and tough. Tree forks are a common feature formed in tree crowns, being the structural attachment of branches to parent stems (main stem) in which there two arising branches have more-or-less equal diameter. The division of a single 
parent stem into two branches of nearly equal diameter is known as a bifurcation (Shigo 1989; Jungnikl et al. 2009; Slater and Ennos 2015). Wind load is also a significant effect on the structure of tree forks, since the forks are frequently exposed to large wind forces. In tree forks, particularly, the apex of bifurcations between the stem and branches has the potential to be the site of mechanical failure in trees (Shigo 1989; James 1990; Gilman 2003; Kane et al. 2008; Jungnikl et al. 2009). This is because stem and two arising branches of bifurcations can move independently and show complex sway (oscillate) motions under windy conditions (Spatz et al. 2007; Spatz and Theckes 2013). Thus, the apices of bifurcations may be exposed to large tensile stresses during large sway motions which can result in splitting of the forks when the load on the branches exceeds the strength of wood. To minimize the likelihood of tree failure, trees have an oscillation damping which is an important survival strategy. Damping is the capability of tree structure to absorb energy from wind loading, and thus, large sway energies can be dissipated through the stem and branches (Niklas 1992; James et al. 2006; Spatz et al. 2007; Theckes et al. 2011; Spatz and Theckes 2013). Mass damping, therefore, could lessen the drag acting and the catastrophic oscillation damage on trees (Theckes et al. 2011). However, forks have an adaptive growth (strategy) which is to make secondary thickening at the apex of bifurcations (where two arising branches conjoin) to cope with large wind loads and so reduce the risk of failure and dampen damaging oscillations (Mattheck 1990; Mattheck and Vorberg 1991; Mattheck and Breloer 1994; Morgan and Cannell 1994; Spatz and Bruchert 2000; Dahle and Grabosky 2010). Thus, tree forks may withstand all the stresses and provide both mechanical stability and adaptive growth for the main stem (James 2003; Jungnikl et al. 2009).

Several researchers, therefore, have sought to determine why and how forks failure and how they can be assessed for their risk of failure (MacDaniels 1923-1932; Miller 1959; Shigo 1985; Harris 1992; Hauer et al. 1993; Matheny and Clark 1994; Farrell 2003; Smiley 2003; Kane 2007; Kane et al. 2008; Slater and Ennos 2013, 2015; Slater et al. 2014). In the previous studies, branch-trunk diameter ratio and branch angle have primarily been investigated to identify the best predictor for a fork's strength. A number of researchers have reported that the attachment angle is the most closely related to the strength of attachment (MacDaniels 1923; Ruth and Kelley 1932; Verner 1955; Buckley et al. 2015); however, others found no relationship between branch angle and strength of bifurcation (MacDaniels 1932; Lilly and Sydnor 1995; Gilman 2003; Pfisterer 2003; Kane 2007). On the other hand, some researchers have indicated that the strength of the junction was mainly correlated with an increase in the branch-trunk diameter ratio (MacDaniels
1932; Miller 1959; Shigo 1985; Farrell 2003; Gilman 2003; Kane 2007; Kane et al. 2008; Buckley et al. 2015) in such a way that relatively larger forces were required to pull apart narrow branches attached to thick ones; forks with branches of equal diameter were considered weakest (Matheny and Clark 1994; Gilman 2003; Kane et al. 2008). In a more recent study, Buckley et al. (2015) showed that diameter ratio of branch and branch strength was significantly correlated with each other, but there was a significant negative relationship, in that, higher diameter ratio of the branches failed at lower breaking stresses. A study by Slater and Ennos (2013) also found that diameter ratio is also an important parameter affecting how the forks fail. They suggested that compression failure at the outside of the forks (type I failure) occurred before fracture more often when the diameter ratio was 65-80\%, whereas forks split before compression failure occurred (type II failure) more often at diameter ratios over $80 \%$ (Fig. 1).

Slater and co-workers have recently published a series of papers relating the anatomy and mechanical properties of the wood in hazel forks and their structural properties. Slater and Ennos (2013) first examined the strength and failure mode of hazel forks by pulling them apart, both when intact and after destroying different parts of the fork to quantify the relative importance of three component parts of the fork: resistance to splitting of centrally placed xylem within the bifurcation; resistance to splitting of peripheral xylem in the plane of the bifurcation; and resistance to bending of the wood within

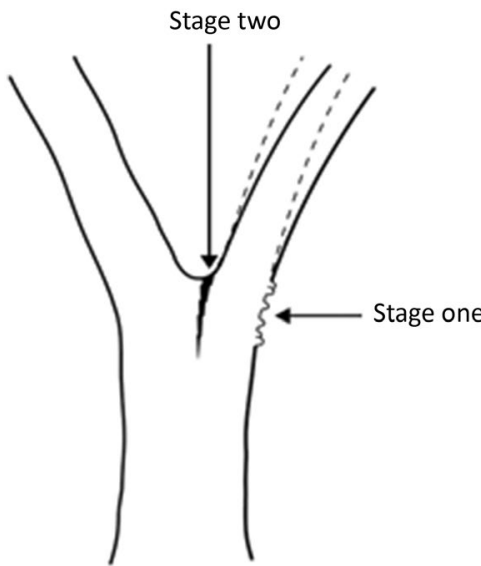

(a)

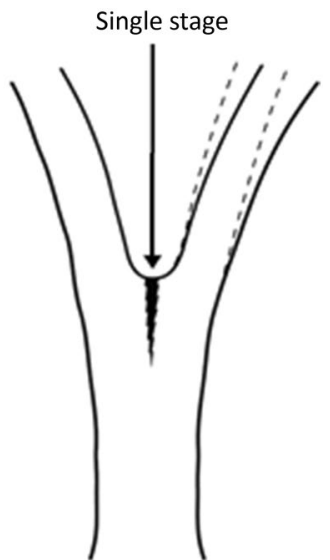

(b)
Fig. 1 Types of tensile failure in tree forks. a In type I mode of failure, the first stage of failure exhibits yielding of wood under the compression of the outer edge of the smaller branch of the fork, prior to the second stage of failure, which is the splitting of the wood at the apex of the joint. b Type II mode of failure in tree forks exhibits only one stage of failure, immediately starting with the splitting of the tissues under tension at the fork apex (Slater and Ennos 2013) 
the bifurcation. The aim of the study was to investigate how forks are designed and how they fail. In this study, they found that, in tensile tests in which the two arising branches were pulled apart, all drilled forks failed in tension at their apex. The main stem split down the middle between the arising branches, and there were no failures in the branches (Fig. 1b). However, intact specimens failed in either type I or type II mode (Fig. 1). In the same study, wood was found to be stronger and denser at the centre of the apex than in the adjacent stem. These researchers suggested that centrally placed xylem in the apical region was the crucial component, contributing a major part of the strength of a tree fork despite making up a small percentage of the centre of the fork. From the results, they concluded that the load-bearing capacity of the forks was mostly obtained from the central apex regions of bifurcations, with the central xylem contributing $35 \%$, the peripheral regions, $50 \%$, while resistance to bending of the wood contributed only around $15 \%$. To determine why this was the case, Slater et al. (2014) examined the anatomy and grain pattern in tree forks. Their anatomical analyses showed that centrally placed xylem at the apex of the bifurcation had more tortuous and interlocked wood grain than wood elsewhere. They found that fork apices also had fewer vessels and smaller sized cells with thicker cell walls than stem wood. The cell wall content was found to be, on average, $28.1 \%$ greater than stem wood. They concluded that this interlocking pattern and tortuosity, together with the higher density, would provide greater transverse wood strength, resisting the splitting of the fork. They also modelled an idealised anatomical cell arrangement of branch attachment which is commonly seen at bifurcation of an angiosperm (Fig. 2b). It can also be clearly seen in Fig. 2a that there is an interlocking wood grain pattern at the centre of the bifurcation. They suggested that this greatly increases the force needed to pull the fork apart at this location, as fibres have to be broken across rather than just separated from each other.

A recent paper by Slater and Ennos (2015) also investigated the contribution of the interlocking wood grain orientation and the patterns at the apex of bifurcations to the wood strength properties in hazel forks. The paper reported that wood did indeed have greater compressive and tensile strength at the apices of bifurcations than either the parent stem or the outer side of the bifurcations, just as predicted by their former paper. Surprisingly, tangential compressive strength of wood was found to be greater than radial at the fork apices. In their anatomical model, they suggested that rays switched their direction and they do not transit the union of two branches at the fork, but deflect to the side of bifurcation.

Wood is a highly complex and orthotropic material with three main directions: longitudinal (L), radial (R), and tangential $(\mathrm{T})$, and six principal fracture systems which are shown in Fig. 3, each characterised by two letters: LR, LT, RL, RT, TL, and TR (in LR, for example, the first letter "longitudinal" indicates the direction
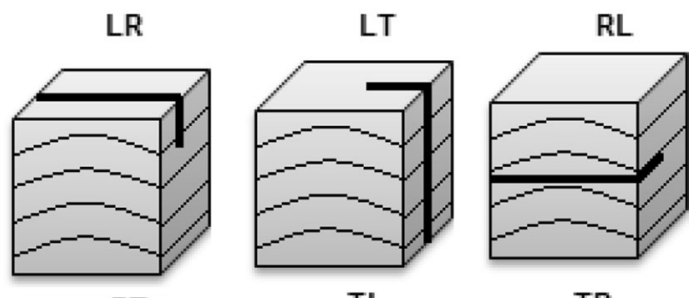

RT
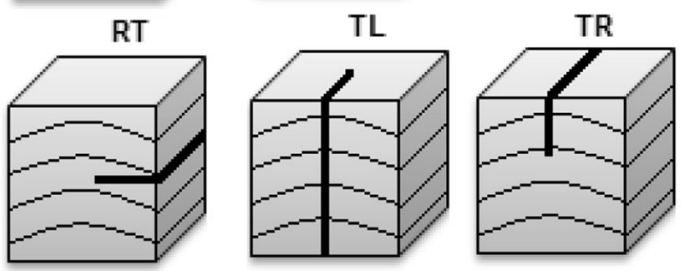

Fig. 3 Fracture systems in wood
Fig. 2 a Simplified pattern of the interlocking wood grain that produces the critical join between branches at the apex of a hazel fork. Note that the route of each grain line passes from the parent stem into one or other arising branch, ensuring all sap-conducting routes run from 'source to sink' as they should. b Schematic diagram of the arrangement of the piths (yellow), vessels (blue), fibres (white), and rays (red) at a fork in Corylus avellana (Slater et al. 2014)

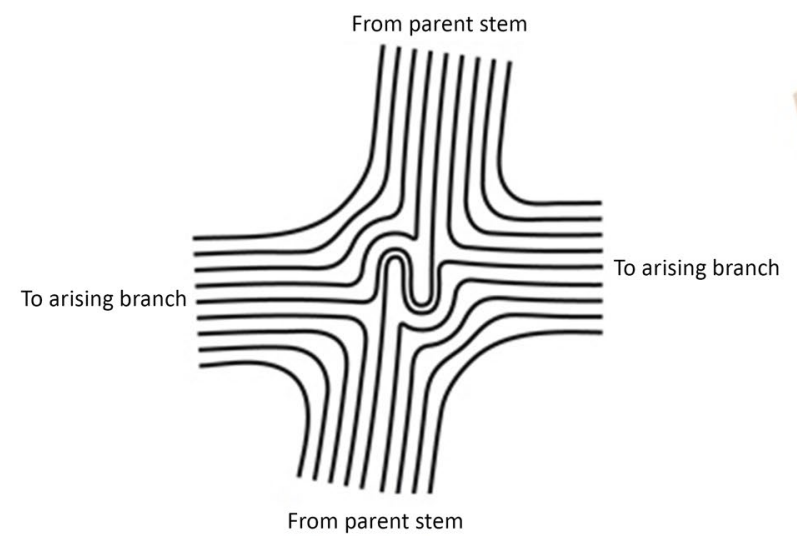

(a)

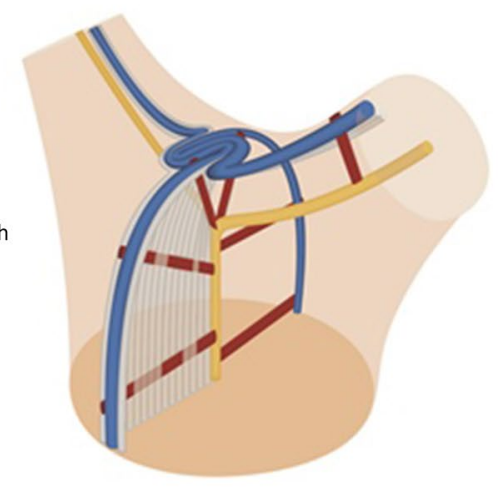

(b) 
normal to the crack plane and the second letter "radial" refers to the direction of crack propagation) (Ashby et al. 1985). The failure behaviour or toughness of wood can show differences depending on the direction of crack propagation, loading method, type of wood species, and anatomy of wood. For instance, wood is usually far more ductile across the grain (LR and LT fracture systems), but brittle along the grain (RL, RT, TL, and TR fracture systems). Results of the previous research has also showed that wood is generally tougher radially than tangentially (Atack et al. 1961; Ashby et al. 1985; Stanzl-Tschegg et al. 1995; Reiterer et al. 2002a, b; Smith and Vasic 2003; Marki et al. 2005; Vasic and Stanzl-Tschegg 2007; Yoshihara and Nobusue 2007; Majano-Majano et al. 2012; Ozden and Ennos 2014; Özden et al. 2016).

Ozden and Ennos (2014) studied the fracture behaviour of green stem wood in three hardwood species-ash, cherry, and birch-in the RT and TR systems using a double-edge-notched tensile test. $G_{\mathrm{f}}$ in RT was found to be almost 1.5 times greater than TR system. They also examined the failure patterns of fracture systems using ESEM micrographs. In their study, RT fractures showed rougher fracture surfaces by ductile failure, due to the presence of spiral failures in the ray cells, which was an evidence in explaining the considerable amount of energy required to break the cells. However, TR fractures had flat surfaces suggesting brittle failure. They suggested that the differences of failure were mostly explained by the rays, which could strengthen and toughen stem wood in the RT system but not in the TR. Note that loading direction is an important parameter affecting the failure behaviour of wood.

To date, several studies have mainly concentrated on the structural strength of tree forks, to explain how and why forks fail and how they develop a best-fit adaptation to lessen the risk of tree failure (MacDaniels 1932; Miller 1959; Shigo 1985; Harris 1992; Hauer et al. 1993; Lilly and Sydnor 1995; Farrell 2003; Smiley 2003; Kane 2007; Kane et al. 2008; Slater and Ennos 2013, 2015; Slater et al. 2014; Buckley et al. 2015). However, there is lack of knowledge concerning the fracture mechanism around the tree forks. To fully determine why forks split, it is further important to understand the fracture properties of wood, since when the applied load reaches the maximum stress (specified upper limit) and exceeds the load capacity, wood will fail completely (Anderson 2005; Sinha et al. 2012). Toughness is a central concept of the fracture properties of wood, because it is a mixture of both strength and ductility and is a measure of how much energy is required to break wood (Singh et al. 2011). Toughness can also be defined as the ability of wood to absorb energy as a crack is propagated during fracture. Basically, toughness can be quantified using specific fracture energy (expressed as $G_{\mathrm{f}}, \mathrm{Jm}^{-2}$ ) which is one of the most commonly used measures or parameters in fracture mechanics - this is the energy required for crack propagation in a unit fracture area of the whole fracture process zone until complete separation occurs.

Therefore, the aim of this study was to investigate how and why the fracture properties vary around the structure of forks of common hazel (Corylus avellana L.) trees in the green condition. Here, we compared $G_{\mathrm{f}}\left(\mathrm{Jm}^{-2}\right)$ between five sampling locations around tree forks and two fracture systems (RT- radial-tangential and TR-tangential-radial). We measured $G_{\mathrm{f}}$ of wood using double-edge-notched tensile tests. The fracture surfaces of the samples were also examined using the scanning electron microscopy technique (SEM) to determine the influence of wood anatomy and microstructure on the failure patterns and toughening mechanism of specimens. The forks of hazel were studied particularly, because this study was carried out in conjunction with the previous studies by Slater and Ennos 2013, Slater et al. 2014, Slater and Ennos 2015 and Buckley et al. 2015 which investigated the strength and failure mode properties of hazel forks in detailed. Together those previous studies, this research will provide broad understanding in the mechanism of tree forks. When we understand and know how toughness is distributed around such forks and the manner in which they are toughened, we may understand better how forks are strengthened against splitting and how man-made joints in composites might be strengthened.

\section{Materials and methods}

\section{Study site and tree}

On 21 July 2014, tree forks were sampled in green condition from 30 forks of hazel (Corylus avellana L.), growing at Myerscough College, Lancashire (Grid Ref: SD49422 40170), England. The age of the forks collected ranged from 6 to 17 years. Each fork was obtained from a different tree, and all forks were situated between 0.5 and $1.8 \mathrm{~m}$ above ground level. The crowns of the trees, where these forks were obtained, were between 6 and $8 \mathrm{~m}$ in height. Upon cutting, each fork was placed in a plastic bag to reduce sap loss, and then placed in a cold store kept at $2^{\circ} \mathrm{C}$ prior to measuring, dissection, and testing.

All the specimens formed "Y" shapes as each fork consisted of one parent stem and two upright branches. Branches were classified as "Branch A" and "Branch B" based on their diameters (Slater and Ennos 2013): Branch A was selected as the branch with the larger diameter (Fig. 4, A1 and A2), and Branch B was selected as the branch with the smaller diameter (Fig. 4, B1 and B2). The outside bark diameter measurements of the parent stem and two arising branches were conducted using a digital calliper in such a way that the diameters of each branch (A and B) 

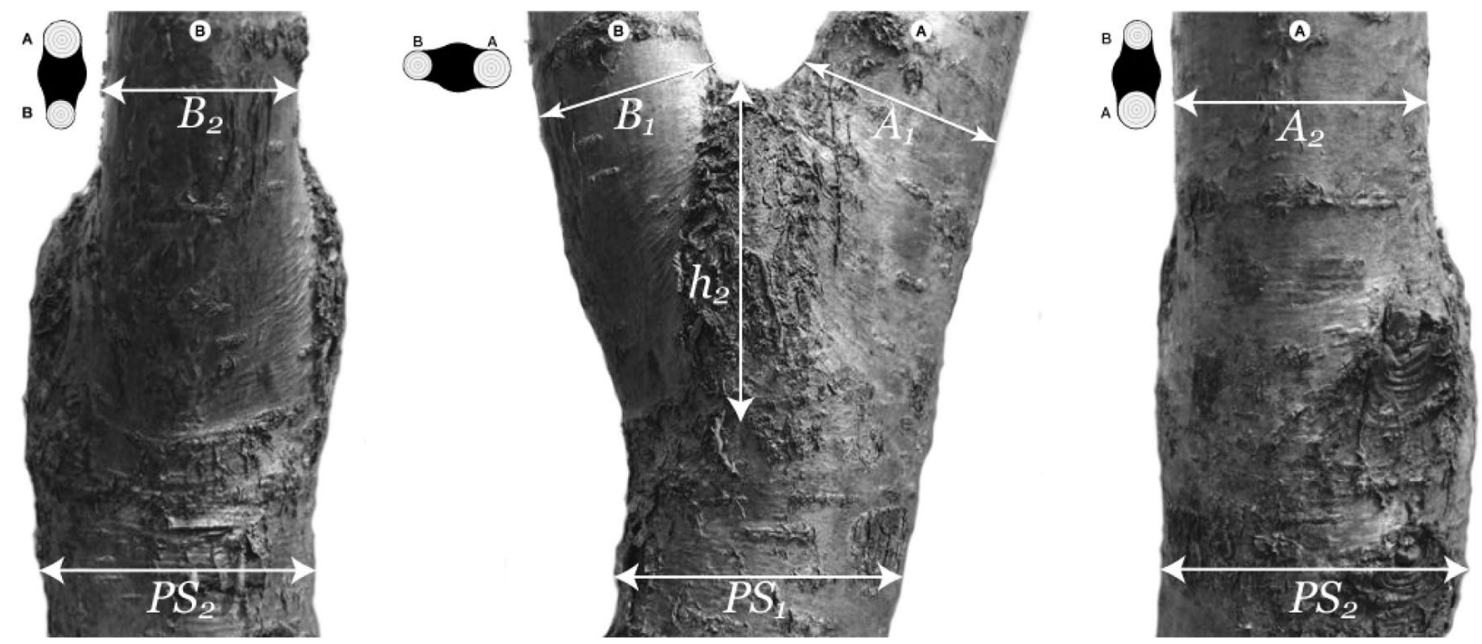

Fig. 4 Diagram illustrating diameter measurements taken for each fork, around its junction. The larger member was labelled as 'A', the smaller branch as 'B', for ease of reference. Lengths $B 1$ and $A 1$ were

were measured just above the bifurcation, both in the plane and perpendicular to the plane of the bifurcation, then the values averaged; and the diameter of the parent stem was measured just below the stem bark ridge both in the plane (Fig. 4, PS1) and perpendicular to the plane of the fork (Fig. 4, PS2), then the values averaged. To prevent moisture loss as far as possible until tests were performed, each sample was kept moist in a cold room at $4{ }^{\circ} \mathrm{C}$ and stored separately in large plastic bags. Forks of the common hazel were chosen in particular for this experiment, because they are common features of the crown structure of this species, and can be sustainably sourced by coppicing the hazel trees in which they form.

\section{Sampling and measuring specific fracture energy $\left(G_{f}\right)$}

The specific fracture energies of wood were investigated between five different sampling locations and two fracture systems to determine how $G_{\mathrm{f}}$ varies around the fork structure. The details of sampling locations, positions, and fracture systems are given in Fig. 5. Each tree fork was first cut into approximately 5-mm-thick discs parallel to the plane of the fork with a metal cutting bandsaw (Fig. 5a). From each fork, 12 sample discs were taken: two discs were cut from the apex of the bifurcations, one being as close to the apex of the bifurcation as possible and the second just below (Fig. 5a), two discs were also cut approximately two parent stem diameters below the apex of the stem (Fig. 5a), and four discs from each branch were cut about two diameters above the apex of the bifurcation (Fig. 5a). Therefore, a total 360 discs were obtained. From those sample discs, cuboids of wood which were $18 \times 10 \times 5 \mathrm{~mm}^{3}$ in dimension were extracted using a fret saw. the shortest diameters across the two branches just above the point of attachment (Slater and Ennos 2013)

At the apex of bifurcation, the bifurcation consists of two piths in a parent stem; from the same apex discs; therefore, two cuboids of wood were taken, such that one sample was cut from between two piths classified as the "central apex" and another was taken from the outer side of the apex of bifurcation classified as "side apex" (Fig. 5c, Apex of bifurcations sampling). From the discs of parent stem, about two diameters below the bifurcation classified as "stem middle" and from the discs of both branches, about two diameters above the bifurcation classified as "branch A" and "branch B". The cuboids were also oriented in two fracture systems for each five sampling locations: RT (radial-tangential) and TR (tangential-radial). Samples from the side apex were not quite perpendicular to the fibres there because of the outward splay of the two branches (Fig. 5), but the angle was small, so that failure would readily occur perpendicular to the fibres even in these specimens. Cuboids could not be cut both radially and tangentially from the same disc in the central apex region of bifurcation, because the diameter of central apex locations (cross section) was not big enough to extract two cuboids of wood in the centre. Therefore, the 30 hazel forks were separated into two groups, excising the wood cuboids in two ways. In 15 of the forks, the long axis of the cuboids cut from the upper disc was orientated in the RT fracture system [Fig. 5c, type 1, (1) Disc] at the central apex and TR fracture system at the side apex, while those cut from the lower disc was orientated in the TR system at the central apex and RT system at the side of the apex [Fig. 5c, type 1, (2) Disc]. In the other 15 , the cuboids were cut in the opposite orientation in the two discs, TR central and RT side apex in the upper disc (Fig. 5c, type 2, (1) Disc) and RT central and TR side apex in the lower (Fig. 5c, type 2, (2) Disc). 


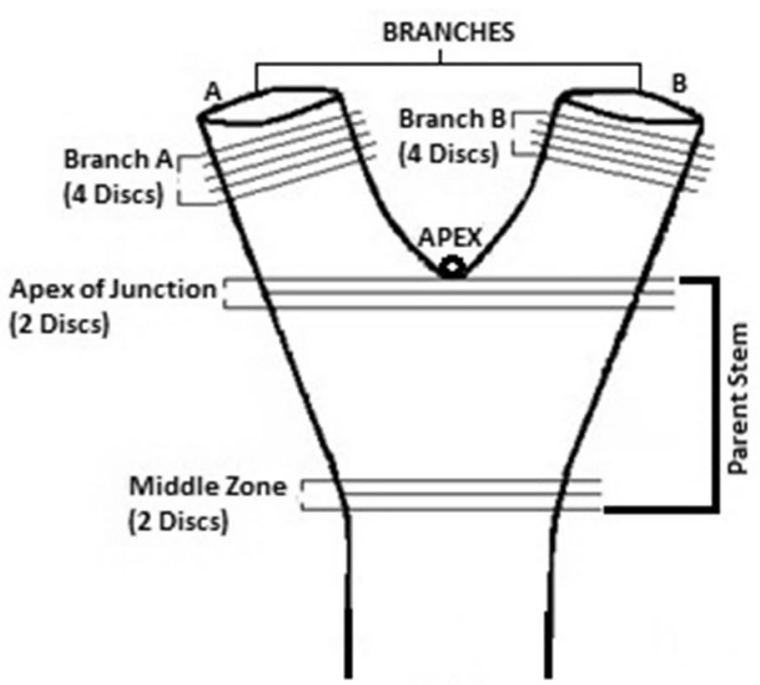

(a)

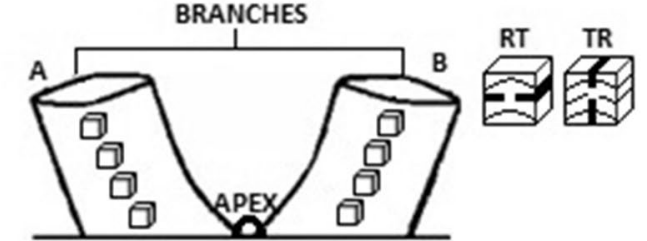

Branches Sampling

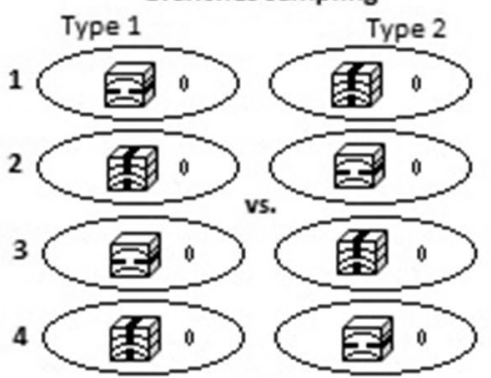

(b)

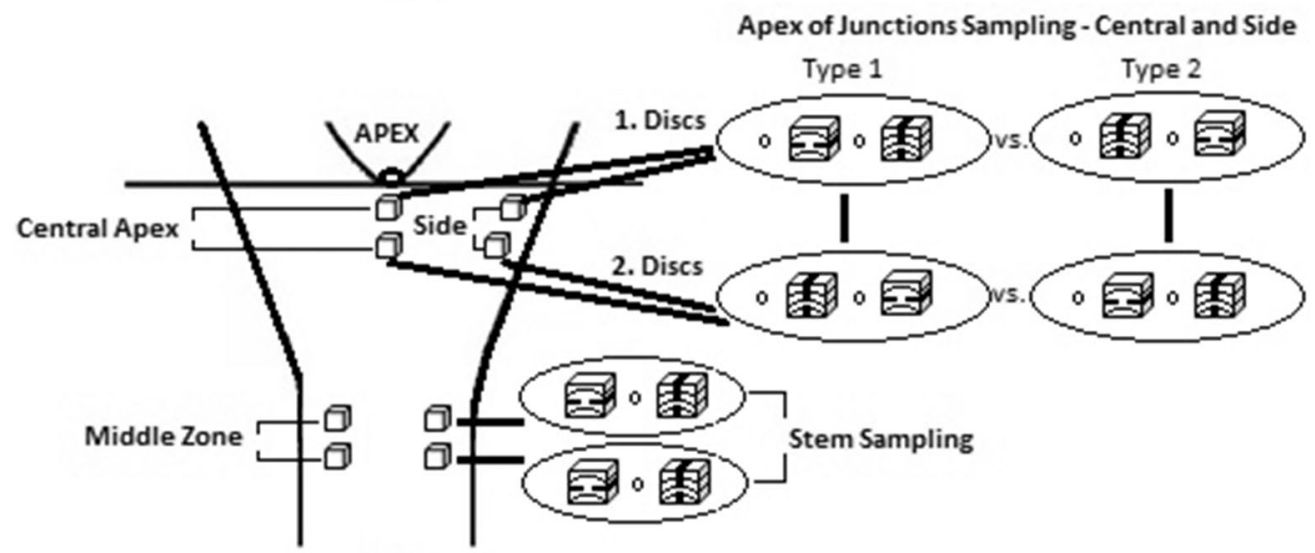

(c)

Fig. 5 Illustration of preparation technique for 30 forks samples in RT and TR systems. a 12 discs were cut parallel to the bifurcation for each fork. b Sampling of branch woods: type 1 was used in first 15 forks and other 15 forks had type 2 sampling. c Sampling of the

This allowed us to overcome the problem that wood in the two discs probably had different anatomy and mechanical properties. However, it was not possible to distinguish fracture systems at the central apex region of the bifurcation by their arrangement of rays, so we identified the central apex RT specific fracture energy as being perpendicular to the bifurcation and the TR specific fracture energy as being in-line with the bifurcation (Slater and Ennos 2015). Unlike the central apex regions, it was easy to identify RT and TR systems at the side apex, stem middle, branches A and B, because growth rings' and rays' arrangement were clearly seen in those locations. From a parent stem again, about two diameters below the bifurcations classified as "stem middle", two cuboids were taken from a one disc in both RT and TR fracture systems (Fig. 5c, Stem sampling). apex of junctions as being central or side in two types: first 15 forks had type 1 sampling and other 15 had type 2 sampling; and stem sampling: both directions were excised from a one disc

Thus, a total of eight specimens were obtained from the parent stem, half being from apex discs, and the other half is from the middle zone of the parent stem (two diameters below the apex of the bifurcation which is called stem middle). Further to this, in both branches, from a one disc, one orientation was sawn. Cuboids again could not be cut both radially and tangentially from the same disc, because the diameters of the branches were quite small. Thus, in 15 of the forks, about two diameters above the apex of the bifurcation, cuboids cut from the upper disc were oriented in the RT system and in the lower disc were oriented in the TR system (Fig. 5b, type 1, Branches sampling). In the other 15 branches (branches A and B), the cuboids were cut in the opposite orientation, TR in the upper disc, and RT in the lower (Fig. 5b, type 2, Branches sampling). Therefore, 
four cuboids were cut out of both branches of each fork, half being RT oriented, and the other half TR orientated.

\section{Density measurements}

The test specimens were saturated with water in airtight storage containers until all were fully hydrated. To ensure the specimens were fully hydrated, they were weighed at 6-h intervals over a period of 1-2 day until mass was constant. We used the water displacement method to determine the wet volumes of specimens. The wood specimens were immersed in water using a needle in a beaker placed on an electronic weighing balance that gave mass of water displacement. After the tensile tests, the specimens were ovendried at $65-70^{\circ} \mathrm{C}$ for $2-3$ days until dry and then weighed. The specimens' densities were calculated by dividing the oven-dried mass to fresh volumes.

\section{Tensile tests}

Specific fracture energies were measured using doubleedge-notched tensile tests which was the same technique as that used by Ozden and Ennos (2014) and Özden et al. (2016) to investigate stem wood. Prior to performing tensile tests, the wooden cuboids were turned into doubleedge-notched test specimens by sawing two notches on either side (Fig. 6b) and sharpening the tip of these notches using a steel razor blade. Starter cracks had a length of 2.0-2.5 mm to give a central ligament length of around 5-6 mm (Fig. 6b). The specimens at the central apex, however, which were found to have a much higher $G_{\mathrm{f}}$, had slightly longer starter cracks to reduce the length of the ligament and hence the tensile forces needed to break them.

To obtain $G_{\mathrm{f}}$ values of specimens, the specimens were clamped to the moveable crosshead and base of a Universal Testing Machine (INSTRON 3344) equipped with a
$1 \mathrm{kN}$ load capacity and attached to an interfaced computer (Fig. 6a). Because of the small size of the specimens, two supporter specimens which had the same thickness as the test specimens were also attached at the other end of the clamps to hold the jaws parallel and ensure that the specimens did not pull out of the clamps (Fig. 6a). The upper jaws were then pulled upwards at a rate of $3 \mathrm{~mm} \mathrm{~min}^{-1}$ until the specimen failed. At the same time, an interfacing computer recorded the displacement and load using the Bluehill 3 Testing Software. After the end of each test, the ligament length of specimen was recorded. The total work $\left(W_{\mathrm{f}}\right)$ under the load-displacement curve was also obtained by integrating the area under the force/extension curve. Specific fracture energy $\left(G_{\mathrm{f}}\right)$, ultimately, was calculated as follows:

$G_{\mathrm{f}}=\frac{W_{\mathrm{f}}}{A_{\text {lig }}}$

where $W_{\mathrm{f}}$ is a total work (dissipated energy), $A_{\text {lig }}$ is ligament area.

\section{Statistical analysis}

For the statistical analysis of the experiments, data were subjected to ANOVA (analysis of variance) and post hoc Tukey tests using the SPSS V 20 software. Differences between groups were considered significant at $p<0.05$.

\section{Results}

\section{Sample morphological parameters}

The forks that were sampled were typically $31 \mathrm{~cm}$ in length, the parent stem and both branch lengths being on average 15.7 and $15.3 \mathrm{~cm}$, respectively. The distance between two
Fig. 6 Drawing of the tensile test procedure

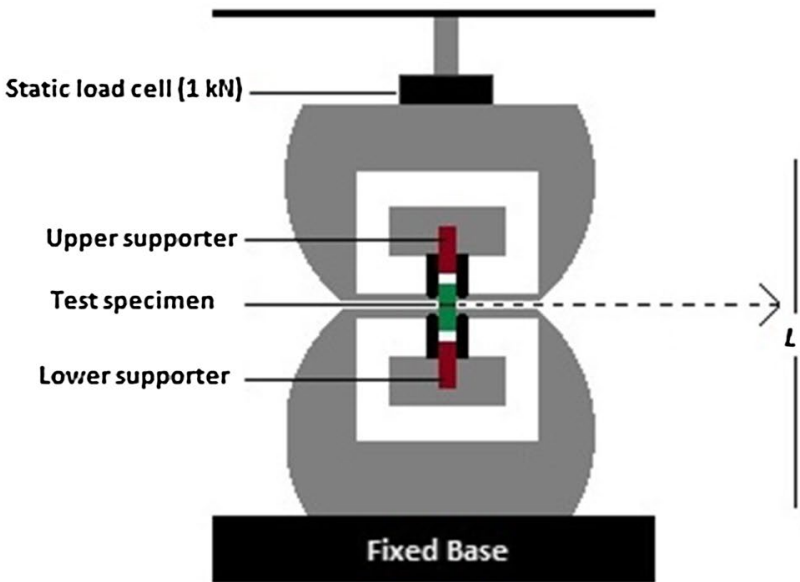

(a)

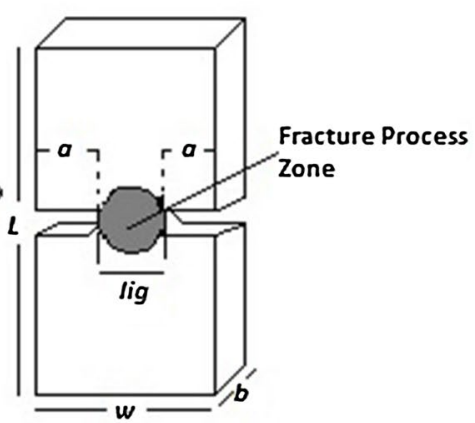

(b) 
branches from their tips and the initial angle of bifurcation were measured; the mean length between branches was $14.7 \mathrm{~cm}( \pm 3.8 \mathrm{SD})$ and the mean angle between the parent stem and branches was $66.9^{\circ}( \pm 12.1 \mathrm{SD})$. The mean diameter of the parent stem was found to be on average $52.4 \mathrm{~mm}$ $( \pm 12.5 \mathrm{SD})$, of branch $\mathrm{A}$, on average $39.6 \mathrm{~mm}( \pm 8.1 \mathrm{SD})$, and of branch $B$ on average $32.6 \mathrm{~mm}( \pm 6.3 \mathrm{SD})$. The diameter ratio of the two arising branches to the parent stem was also measured as the average diameter of each branch just above the bifurcations divided by the average diameter of the parent stem just below the stem bark ridge. The mean diameter ratio of branch A to parent stem was found to be $76.7 \%$ ( $\pm 7.7 \mathrm{SD}$ ), ranging from 58 to $91 \%$; and the mean diameter ratio of branch $\mathrm{B}$ to stem was found to be $63.3 \%$, ranging from 51 to $81 \%( \pm 8.1 \mathrm{SD})$.

\section{Tensile tests}

In total, 480 specimens from 30 hazel forks were tested using a tensile test to estimate the specific fracture energies $\left(G_{\mathrm{f}}, \mathrm{Jm}^{-2}\right)$. The specimens were taken from different locations around the forks: at the central apex of the bifurcation, side apex of the bifurcation, middle region of parent stem (stem middle), and branches A and B.

As noted above, apex discs were prepared in two positions: upper and lower (U vs. L), because it was not possible to excise both RT- and TR-oriented specimens from central and side apex locations. Thus, we conducted a three-way ANOVA between the central and side apex of bifurcation to explore the effects of types (central vs. side), fracture systems (RT vs. TR), and positions ( $\mathrm{U}$ vs. L) on $G_{\mathrm{f}}$ values. Table 1 presents the summary of mean $\mathrm{G}_{\mathrm{f}}$ values in the two fracture systems (RT vs. TR) and positions ( $\mathrm{U}$ vs. $\mathrm{L}$ ) for both central and side apex of bifurcation obtained for 120 specimens. The results of three-way ANOVA results indicated that $G_{\mathrm{f}}$ differed significantly between the four locations (central RT, central $\mathrm{TR}$, side RT, and side TR) $[F(3,112)=127.95 p<0.001]$; but there was no significant effect of positions (U vs. L) on $G_{\mathrm{f}}[F(1,112)=0.24 p=0.621]$. A post hoc Tukey tests showed that all locations were significantly different from

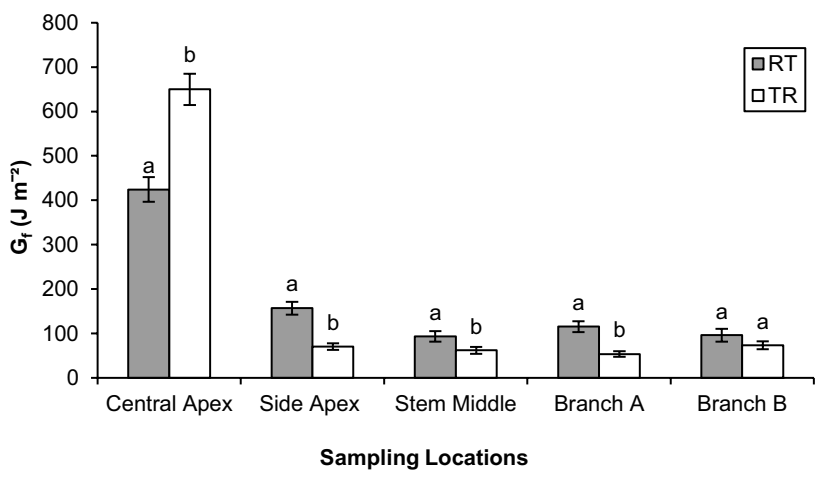

Fig. $7 G_{\mathrm{f}}$ results of 480 specimens from 30 forks in different sampling locations and systems. Central Apex $(n=60)$, Side Apex $(n=60)$, Stem Middle $(n=120)$, Branch A $(n=120)$, and Branch B $(n=120)$. Error bars represent the standard error. Results of post hoc Tukey tests are denoted using letters; columns labelled with the same letter present no significant difference and values with different letters show a statistically significant difference at $p<0.05$

each other $(p<0.05)$; particularly, overall, mean $\mathrm{G}_{\mathrm{f}}$ was almost 4.7 times higher at the central apex of the bifurcations than the side apex of the bifurcations. There was also a significant difference in mean $\mathrm{G}_{\mathrm{f}}$ values between fracture systems $[F(1,112)=44.92 p<0.001]$.

It can be clearly seen in Fig. 7 that large differences were found in $G_{\mathrm{f}}$ values between the five locations (central apex, side apex, stem middle, branch $\mathrm{A}$, and $\mathrm{B}$ ). Differences between means were tested using a oneway ANOVA which showed that $G_{\mathrm{f}}$ significantly varied between locations (central apex, side apex, stem middle, branch A, and branch B) $[F(4,470)=211.76 p<0.001]$. The wood of the central apex was much tougher than elsewhere; overall, a mean of $537.1 G_{\mathrm{f}}$ was found for the central apex, $113.9 G_{\mathrm{f}}$ for the side of bifurcations, $77.9 G_{\mathrm{f}}$ for the stem middle, and $84.8 G_{\mathrm{f}}$ for the branches. A post hoc Tukey test for significance also indicated that the wood that was excised from the central apex of the forks were significantly tougher than that of the four other locations; however, no significant difference was found in average $G_{\mathrm{f}}$ values between the side apex, stem middle, and both branches $(p>0.05)$.
Table 1 Specific fracture energies for central and side apex of bifurcations in two positions (upper vs. lower) and systems (RT vs. TR) $($ mean \pm standard error $(\mathrm{SE})$, $n=15$ )

\begin{tabular}{lll}
\hline Sampling locations & RT Gf $\left(\mathrm{J} \mathrm{m}^{-2}\right)$ & TR Gf $\left(\mathrm{J} \mathrm{m}^{-2}\right)$ \\
\hline Central apex of bifurcations & & \\
$\quad$ Upper (U) & $358.15 \pm 31.25(n=15) \mathrm{b}$ & $676.82 \pm 59.42(n=15) \mathrm{a}$ \\
$\quad$ Lower (L) & $490.36 \pm 40.03(n=15) \mathrm{b}$ & $622.57 \pm 38.98(n=15) \mathrm{a}$ \\
Side of bifurcations & & \\
Upper (U) & $175.87 \pm 23.42(n=15) \mathrm{c}$ & $67.83 \pm 5.06(n=15) \mathrm{d}$ \\
Lower (L) & $138.66 \pm 16.16(n=15) \mathrm{c}$ & $73.25 \pm 56.10(n=15) \mathrm{d}$ \\
\hline
\end{tabular}

Statistical differences were determined by a one-way ANOVA $(p<0.005)$ and post hoc Tukey tests (confidence interval: $95 \%$ ). Locations with significant differences in each column are denoted by different letters 
A comparison of RT and TR $G_{\mathrm{f}}$ values between central apex, side apex, stem middle, and both branches (A and B); locations also showed interesting patterns. Surprisingly, at the central apex, $G_{\mathrm{f}}$ was found to be significantly higher in the TR system than the RT system using a one-way ANOVA $[F(1,58)=25.18 p<0.001]$; TR $G_{\mathrm{f}}$ was overall $53.1 \%$ greater than the RT system. In contrast, a one-way ANOVA for the side apex of bifurcations showed more than twice $G_{\mathrm{f}}$ in the RT system than the TR system $[F(1,58)=28.41 p<0.001]$, as would be expected for normal wood. Similar to the side apex, $\mathrm{RT} \mathrm{G}_{\mathrm{f}}$ was found to be greater than TR for both the stem middle $[F(1,118)=4.88$ $p=0.029]$, and branch A $[F(1,118)=19.96 p<0.001]$, but no significant difference was found in branch $B$ $[F(1,118)=1.83 p=0.178]$. We also conducted a two-way ANOVA between the side apex, stem middle, and branches $\mathrm{A}$ and $\mathrm{B}$, because those locations showed almost similar failure patterns in their $G_{\mathrm{f}}$ values. Overall, mean $\mathrm{G}_{\mathrm{f}}$ differed significantly between locations $[F(3,412)=2.84 p=0.037]$ and fracture systems $[F(1,412)=38.61 p<0.001]$. A post hoc Tukey tests found no significant differences on $G_{\mathrm{f}}$ between side apex, branch A, and branch B $(p>0.05)$; however, $G_{\mathrm{f}}$ was found to be significantly lower in the stem middle than other three locations. Load-displacement curves with the maximum loads at the breaking points were obtained for the specimens made of five sampling locations and two fracture systems. Typical load-displacement curves for each sampling location for TR fracture system are shown in Fig. 8. The specimens of central apex wood showed quite ductile failure fashion in both TR and RT fracture systems. Central apex woods showed more likely ductile failure manner with higher energy consumption. The cracks propagated unstably and the force decreased slowly with high loads. In contrast, the woods of side apex, stem middle, and both branches showed more likely brittle failure manner. There was a slower drop in the force after peak loading. The maximum loads also showed differences depending on sampling locations and fracture systems. Each specimen had different maximum loads in tow fracture systems. Central apex had higher maximum loads in their TR fracture system than RT system. However, side apex, stem middle, and both branches showed higher values in the RT system than TR system. The values vary from an average of 40-96 N; TR fracture of central apex showed the highest loads with a value of $96 \mathrm{~N}$ and TR fracture of branch A exhibited the lowest. Particularly, the mean maximum load for the TR fracture of central apex was approximately two times greater than other four locations.

\section{Wood density}

Among all locations, the mean density was found to be higher at the central apex regions of bifurcations with mean $0.66 \mathrm{~g} \mathrm{~cm}^{-3}$ (Fig. 9). A one-way ANOVA found significant differences in densities between the five locations $[F(4$, $475)=47.47 p<0.001$ ]; and post hoc Tukey tests indicated that central apex locations had significantly higher wood densities than side apex (mean $0.58 \mathrm{~g} \mathrm{~cm}^{-3}$ ), stem middle (mean $\left.0.56 \mathrm{~g} \mathrm{~cm}^{-3}\right)$, branch A $\left(0.54 \mathrm{~g} \mathrm{~cm}^{-3}\right)$, and branch B $\left(0.53 \mathrm{~g} \mathrm{~cm}^{-3}\right)$, respectively $(p<0.0010 .000)$. However,
Fig. 8 Typical load-displacement curves of wood specimens from five different sampling locations for the TR fracture system

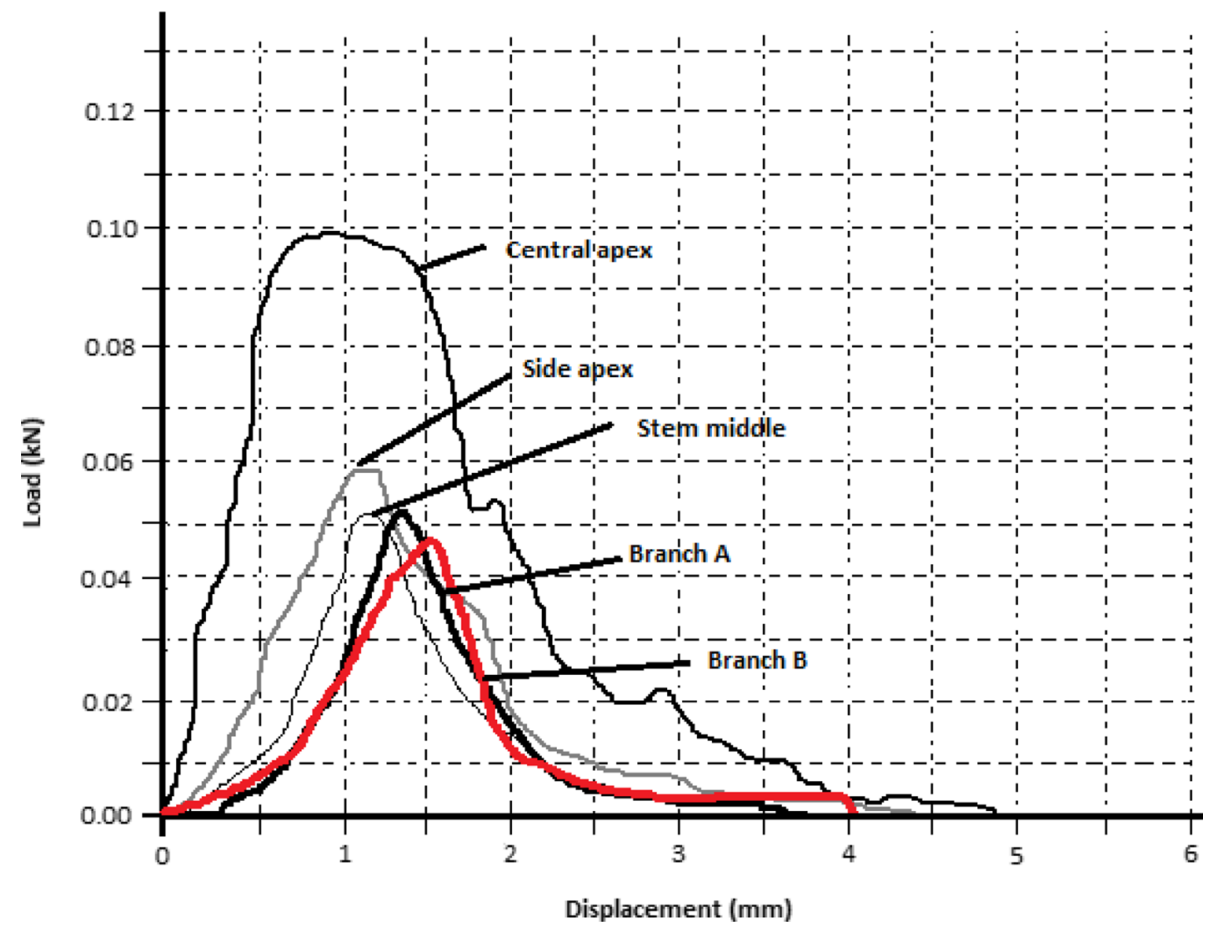




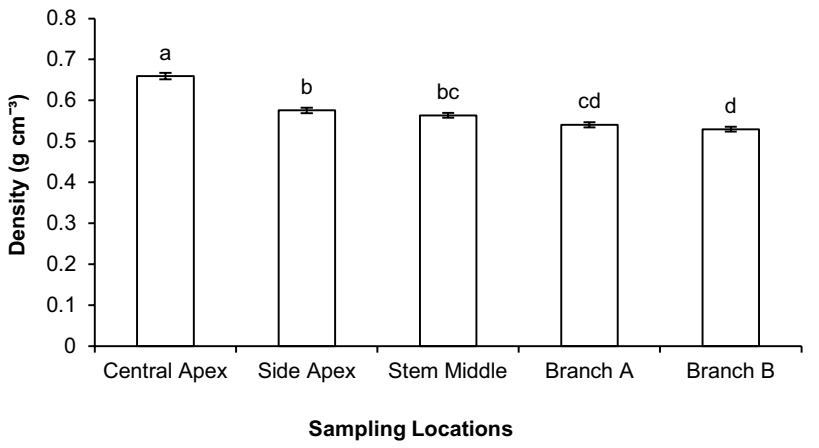

Fig. 9 Density results of 480 specimens from 30 forks in different sampling locations. Central Apex $(n=60)$, Side Apex $(n=60)$, Stem Middle $(n=120)$, Branch A $(n=120)$, and Branch B $(n=120)$. Error bars represent the standard error. Results of post hoc Tukey tests are denoted using letters; columns labelled with the same letter present no significant difference and values with different letters show a statistically significant difference at $p<0.05$

though wood density was significantly higher at the side apex than both branches, no significant difference was found with the stem $(p=0.733)$.

\section{Discussion}

Our results show how toughness varies around the hazel forks, helping us to understand how the branch-stem joint helps the tree to survive. Figure 7 shows the comparison of $G_{\mathrm{f}}$ values measured for all 480 wood specimens between five different locations (central apex, side apex, stem middle, branch A, and branch B) and two fracture systems (RT vs. TR). Under tensile loading, each location exhibited clear differences in their $G_{\mathrm{f}}$ values: the wood of the central apex was found to have the highest mean $G_{\mathrm{f}}$ values, but others showed much lower values. The failure mechanism also differed in the five locations: wood behaved mostly in a ductile failure manner, because the mixed wood grain orientation could make the wood tougher at the central apex of bifurcations, while others showed mostly brittle failure. Interestingly, a comparison of $G_{\mathrm{f}}$ values between RT and TR fractures for each location also revealed surprising failure patterns and manners: although the wood was mostly tougher in the RT system than the TR system for the side apex, stem middle, and both branches; exceptionally, $G_{\mathrm{f}}$ values obtained at the central apex were found to be higher in the TR fracture system than the RT system. The differences in $G_{\mathrm{f}}$ values between locations and fracture systems, reported here, could be partly explained by the density (Fig. 9) (for central apex which is also much tougher than other locations, but there is no pronounced difference in density between side apex, stem middle, and both branches), fracture surfaces and microstructure of wood in the different locations.

Overall, in the central apex, wood had about five times greater mean $G_{\mathrm{f}}$ than the wood of side apex, stem middle, and branches. Our results agree well with the previous studies (Slater and Ennos 2013, 2015; Slater et al. 2014) who found that the central apex wood was stronger than elsewhere. There are possible explanations for the high toughness (expressed as $G_{\mathrm{f}}$ ) values at the central apex. First, the central apex had considerably denser wood than the others: such that overall central apex was approximately $20 \%$ greater than the other locations. It is well known that density is a major indicator affecting wood strength or toughness, such that denser woods are generally stronger and tougher (Panshin and de Zeeuw 1980; Ashby et al. 1985; Desch and Dinwoodie 1996; Dinwoodie 2000; StanzlTschegg and Navi 2009). This is because a heightened wood density indicates a higher percentage of cell wall volume in the sample, which is formed by cellulose microfibrils and matrix polymers (lignin and hemicelluloses) (Fengel and Wegener 1983); denser woods have much more cell wall material with thicker cell walls, but smaller diameter cell lumens or voids (Gartner 1995; Dinwoodie 2000; Harris 2006). Previous studies suggested that the wall thickness of cells is directly related to failure behaviour of specimens (Smith et al. 2003); that is, the increased cell wall thickness-to-cell diameter ratio can tend to show more resistance to failure of cell walls (Dinwoodie 1965; Jeronimidis 1980; Smith et al. 2003). In the present study, a linear regression analysis was conducted to test if the density significantly predicted the wood's toughness. Overall, the results of linear regression analysis identified that there was a significant positive relationship between toughness and density $(p<0.001)$, but not a strong one that gave a sufficient explanation to the heightened toughness found at fork apices $\left[r^{2}=0.20, F(1,478)=112.46\right]$; this showed that toughness increased with the increasing density of the central apex wood. A similar conclusion was also reached by Slater and Ennos (2013-2015). They found that wood was denser at apical regions of forks which also provided extra strength. Therefore, this aspect of structure had a tendency to prevent splitting of the bifurcation.

During the tests, central apex wood exhibited more difficult fractures and more ductile failure behaviour in both RT and TR fracture systems in tension than that of the other four locations. At the central apex, the crack initiation was relatively slow and the crack could not propagate easily through the ligament plane in that it more often showed progressive failure behaviour until the specimen surfaces were fully separated. The crack thus left more tortuous and jagged fracture surfaces (Fig. 10a). TR fracture surfaces of central apex wood had predominantly a splintering failure manner (Garland 1939; Wardrop 1951) (Fig. 10a), 
Fig. 10 SEM images of the fracture surfaces of broken central apex of bifurcations in the TR fracture systems. $\mathbf{a}$ is a fracture surface of the central apex in the TR system and shows splintered failure manner on the surface. $\mathbf{b}$ shows irregular fracture patterns in fibres. c demonstrates that fibres were split across their length. d shows the spiral failure manner of fibres
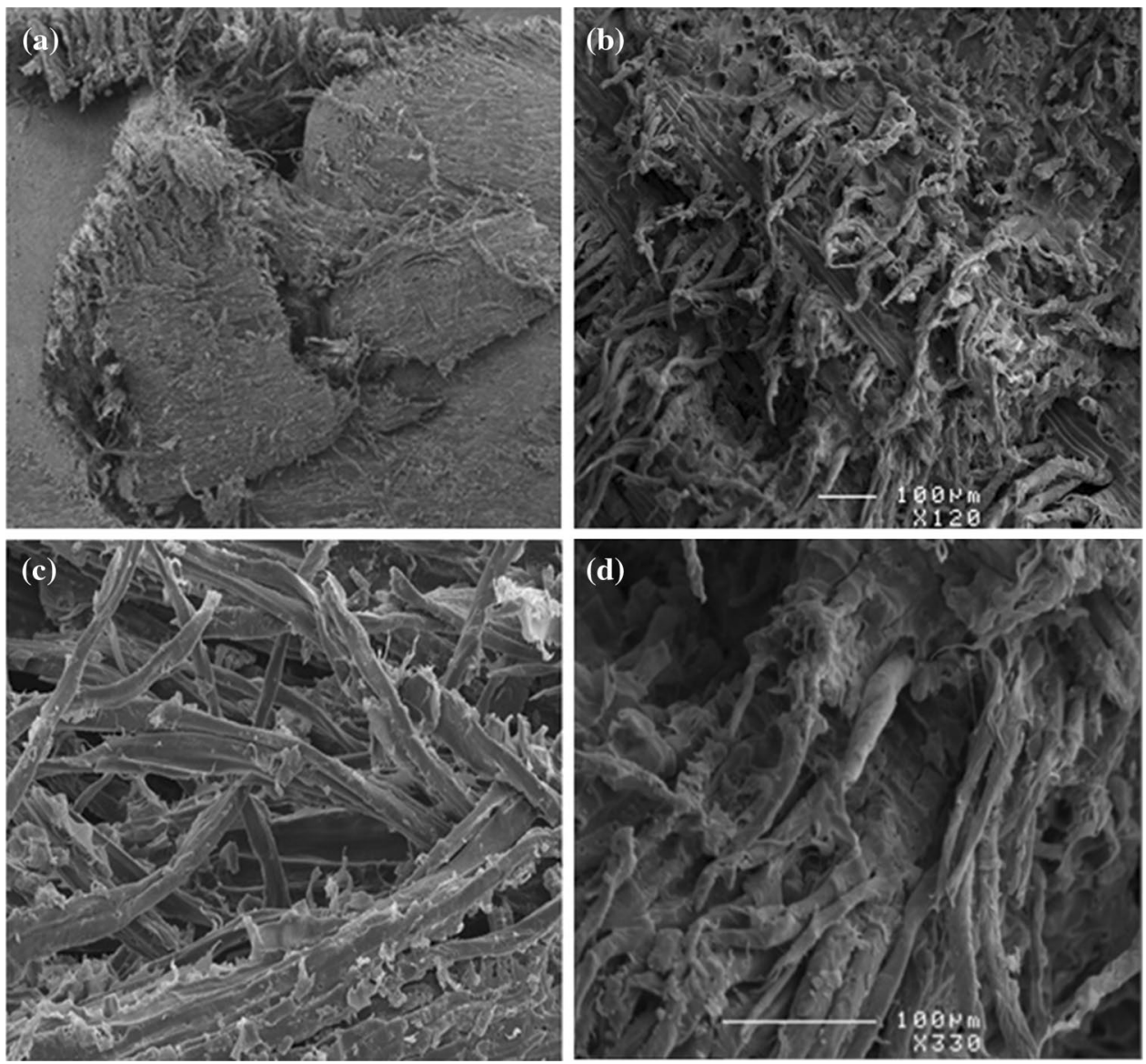

but RT fractures were found to be have a less tortuous and splintered appearance (Fig. 11). The most interesting finding was that the mean $G_{\mathrm{f}}$ of TR was found to be almost 1.5 times bigger than the RT system at the central apex. Mohammadi and Nairn (2014) also reported almost similar observations in the TR and RT fracture systems of balsa stem wood using the Mode I method, such that TR toughness was greater than RT, because cracks did not grow in the TR plane and jumped in the RT plane.

Jeronimidis (1980) observed helical failure patterns of cellulose microfibrils in the secondary wall of sitka spruce in tension. He suggested that helical failure requires huge amounts of energy to propagate cracks, so the helical form of these cells prevents failure. A recent study by Özden et al. (2016) investigated the fracture properties of stem wood of six tree species in the RL and TL fracture systems. They found quite same mechanism in the cell walls of ray cells which failed in helical or spiral failure manner in the RL fracture system, particularly in hardwoods. They suggested that the toughening mechanism of ray cells act like fibres or tracheids which toughen wood in the RL fracture system.

Here, our SEM micrographs provided clear evidences related to the failure behaviour of wood specimens and fracture systems. At the cellular level, cells showed more intrawall failure (within the secondary wall) and less transwall failures (failure cuts across the cell wall). The crack could not propagate readily through the central apex, because more breakage of axial fibres took place. It can be seen in Figs. 10c and 11c that fibres were cut across their length by intrawall failure behaviour. As also shown in Figs. 10d and 11d, central apex fractures were more likely to exhibit spiral or helical buckling failure pattern of cellulose microfibrils (secondary wall). This is because fibres tended to surround the ligament area with unwinding/spiral phenomenon to produce crack stopper interfaces (barriers), and therefore, it could prevent rapid splitting of specimens during crack initiation. During the crack propagation phase, thus, large amounts of energy were consumed to cleave cells and the failure manner of fibres may give an understanding of why they did not break easily at this region.

In addition, there was an interlocked wood grain pattern formation at the central apex. Our fracture surface analyses were in agreement with the study of hazel fork fracture surfaces by Slater et al. 2014. They found that there was an altered interlocking wood grain pattern and more tortuous structure at the central apex. They suggested that the interlocking wood grain pattern and tortuous structure 
Fig. 11 SEM images of the fracture surfaces of broken central apex of bifurcations in the RT fracture systems. a shows hairy and tortuous fracture surface. $\mathbf{b}$ demonstrates spiral failures of fibres the spiral failure manner through the fibre which is unwind or uncurling of the cell walls. c shows that fibres were split across their length and both transwall and intrawall failures occurred in the cells. $\mathbf{d}$ indicates irregular fracture patterns on fibres
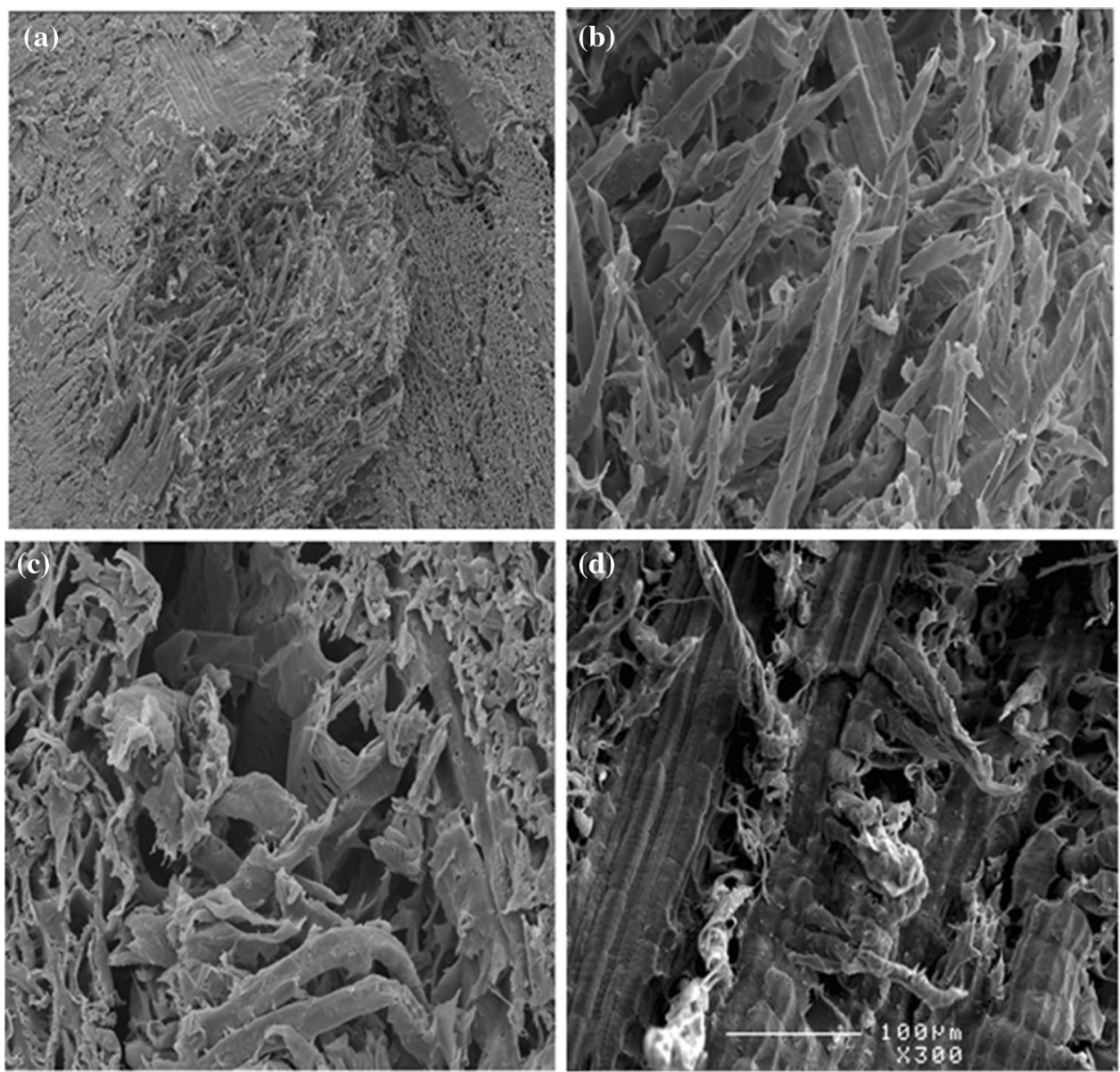

could reinforce the central apex and give an extra strength to hold the branches together. Consequently, the central apex region of the bifurcations could strengthen the loadbearing capacity, and thus, it can provide a self-supported mechanism to balance the union between parent stem and branches safely, due to the combination of high density (so thicker cell walls), more tortuous and interlocked structure, supportive activity of fibres and ductile failure mechanism of the central apex (Shigo 1985, 1989; Carlquist 1991; Gartner 1991a; Desch and Dinwoodie 1996; Jungnikl et al. 2009; Slater and Ennos 2013, 2015; Slater et al. 2014). An anatomical model of branch attachment by Slater et al. (2014) suggested that fibres are preferentially oriented more tangentially than radially in the central apex which could provide extra toughness in this system. However, further studies on the microstructure of RT and TR fracture systems of hazel forks should be made to investigate why the TR fracture system was somewhat tougher.

In contrast to the central apex, the reverse pattern was true for the side apex, stem middle, and both branches, such that those locations resulted in higher $G_{\mathrm{f}}$ values in their RT fractures than the TR fractures. Our results of side apex and parent stem showed similarities to those reported by Slater and Ennos 2015. They also found that wood was stronger radially than tangentially at the both side apex and stem middle. In previous papers, again (Atack et al. 1961; Ashby et al. 1985; Ozden and Ennos 2014), the same pattern was also shown for toughness, namely, the RT toughness of stem wood was found to be greater than TR. Overall, the differences of $G_{\mathrm{f}}$ values were slight between the side apex, stem middle, and branches A and B, because all four locations showed similar low density in their wood compared with the central apex wood. During tensile loading, the crack propagated rapidly and generated premature failures on the specimen in a brittle failure manner. The fracture surfaces thus were fairly smooth and less hairy (Fig. 12). Due to the easy separation of specimens, relatively less energy consumption was required. SEM micrographs provided possible explanations related to how fracture manners differed between two fracture systems and four locations and why easy fractures occurred in those locations (Fig. 12). On a microscopic level, the cell failures were mostly dominated by transwall behaviour and less intrawall manner in all those four locations. It can be easily seen from Fig. 12, the crack propagation induced serious cell and cell wall deformations by easily cutting cell walls 
Fig. 12 SEM images of the fracture surfaces of side apex, stem middle, and two branches in two systems. Picture a shows the RT fracture surface of side apex, $\mathbf{b}$ shows the TR fracture surface of side apex, $\mathbf{c}$ shows the RT fracture surface of stem middle, $\mathbf{d}$ shows the TR fracture surface of the stem, e shows the RT fracture surface of branch $\mathbf{a}$ and $\mathbf{f}$ shows the TR fracture surface of branch A
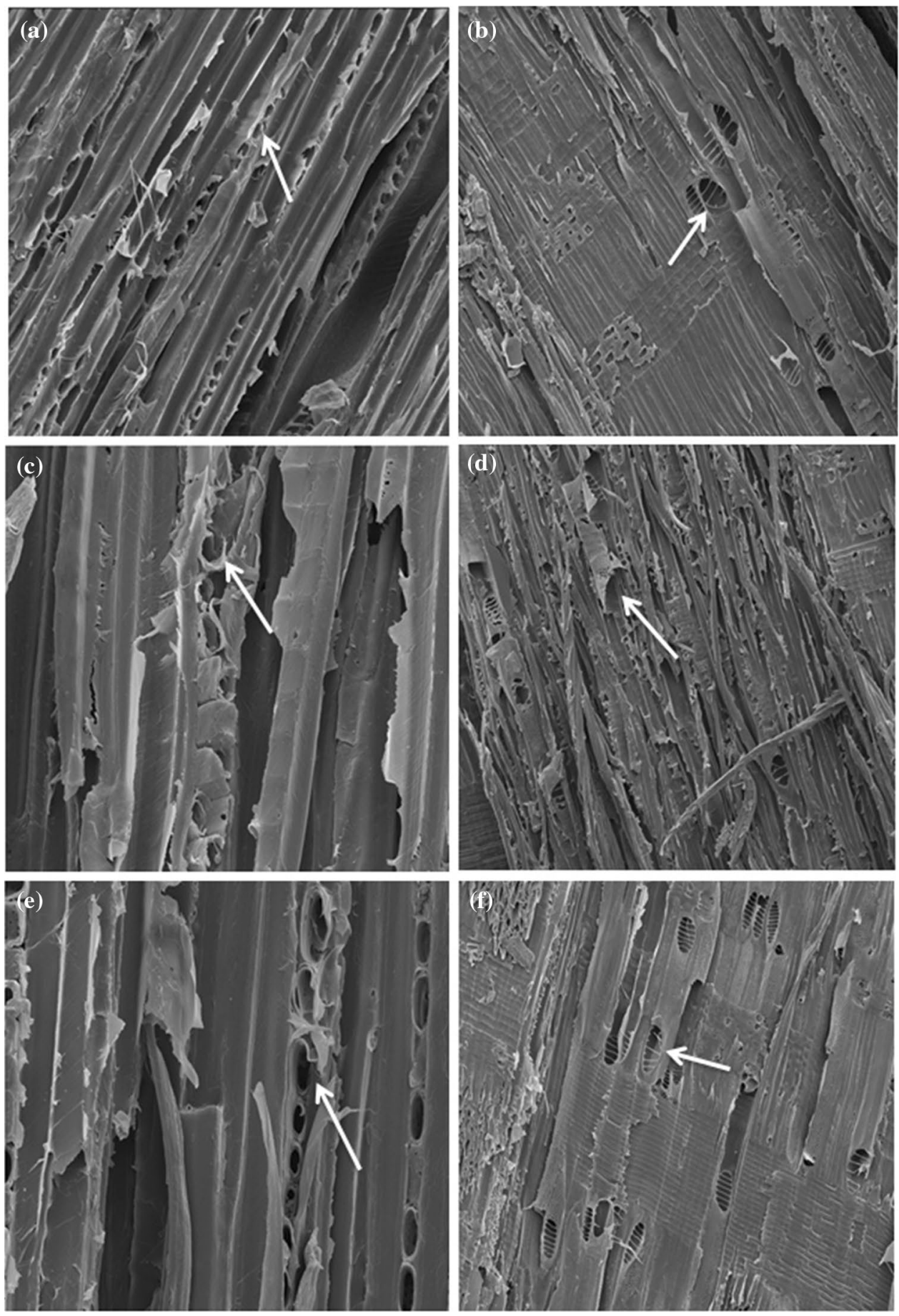

(transwall failures) in both RT and TR fracture systems. In the case of those locations, we can also explain the lower $\mathrm{G}_{\mathrm{f}}$ values by the presence of relatively thinner cell walls. Particularly, when loaded in the TR fracture system, fracture generated flatter surfaces (Fig. 12b, d, f). TR micrographs showed that failures occurred more easily by breaking the cells and by transwall failure (Fig. 12b); therefore, serious cell ruptures and deformations occurred (Fig. 12f).
RT of $G_{\mathrm{f}}$ was found to be greater than TR. This difference is probably related to the radially oriented rays which reinforce this crack propagation system and have a supportive property in inhibiting the failure process (Beery et al. 1983; Burgert and Eckstein 2001; Reiterer et al. 2002a, b; Ozden and Ennos 2014). Ozden and Ennos 2014 found rays more likely to show a strengthened factor to resist crack propagation in the RT, whereas the rays in TR are not oriented 
in the right direction to prevent failure. It can be seen in Fig. 12 that RT fracture did not show easily cleaved cells (Fig. 12a, c, e) and exhibited both transwall and intrawall failure modes in the cells. In tension, rays failed helically by intrawall failure (Fig. 12 a, c, e), while vessels exhibited more cell ruptures by easily cutting cell walls with a transwall failure manner (Fig. 12f).

\section{Conclusions}

In conclusion, we investigated fracture energies and toughening mechanism of forks at five different sampling locations and in two fracture systems. It was shown that wood in the central apex of bifurcations was significantly denser and tougher than in the other four locations. The micrographs of SEM also showed interlocking wood grain formation and more helical buckling failure of cellulose microfibrils at the central apex of bifurcations. The findings of this study, therefore, suggest that both higher density and convoluted wood grain made the wood approximately five times tougher at the central apex. $G_{\mathrm{f}}$ was also found to be greater in the TR fracture system than RT system at the central apex. This could be explained by preferential tangential orientation of fibres. However, further anatomical analyses need to be carried out to determine why central apex wood is tougher in the TR fracture system than RT.

Author contribution statement SO designed and performed experiments, analysed data, and wrote the manuscript, and DS and ARE provided sample collection and edited manuscript.

Acknowledgements We would like to thank the following individuals Dr. John Waters of the School of Earth Atmospheric and Environmental Sciences University of Manchester and Tony Sinclair of School of Biological, Biomedical and Environmental Sciences University of Hull for use and assistance of the scanning electron microscopes. Prof. Dr. Ulrich E. Luettge provided useful editorial comments that we gratefully acknowledge. We also would like to thank our anonymous reviewers for the great effort they have put into reviewing our paper.

\section{Compliance with ethical standards}

Conflict of interest The authors declare that they have no conflict of interest.

Open Access This article is distributed under the terms of the Creative Commons Attribution 4.0 International License (http:// creativecommons.org/licenses/by/4.0/), which permits unrestricted use, distribution, and reproduction in any medium, provided you give appropriate credit to the original author(s) and the source, provide a link to the Creative Commons license, and indicate if changes were made.

\section{References}

Anderson TL (2005) Fracture mechanics, fundamentals and applications. CRC Press: Taylor and Frances Group, Boca Raton, FL, pp 122-125, 310-311

Ashby MF, Easterling KE, Harrysson R, Maiti SK (1985) The fracture and toughness of woods. Proc R Soc Lond A 398:261-280

Atack D, May WD, Morris EL, Sproule RN (1961) The energy of tensile and cleavage fracture of black spruce. Tappi 44(8):555-567

Baker CJ (1997) Measurements of the natural frequencies of trees. J Exp Bot 48:1125-1132

Beery WH, Ifju G, McLain TE (1983) Quantitative wood anatomyrelating anatomy to transverse tensile strength. Wood Sci 15(4):395-407

Buckley G, Slater D, Ennos AR (2015) Angle of inclination affects the morphology and strength of bifurcations in hazel (Corylus avellana L.). Arboric J 37(2):99-112

Burgert I, Eckstein D (2001) The tensile strength of isolated wood rays of beech (Fagus sylvatica L.) and its significance for the biomechanics of living trees. Trees 15(3):168-170

Carlquist S (1991) Anatomy of vine and liana stems: a review and synthesis. Putz FE, Mooney HA (eds) The biology of vines. Cambridge Univ Press, Cambridge, p 53-71

Dahle GA, Grabosky JC (2010) Allometric patterns in Acer platanoides (Aceraceae) branches. Trees Struct Funct 24:321-326

Desch HE, Dinwoodie JM (1996) Timber structure, properties, conversion and use 7th edn. Macmillan Press Ltd., London, p 306

Dinwoodie IM (1965) The relationship between fibre morphology and paper properties. Tappi J 48(8):440-447

Dinwoodie JM (2000) Timber, its nature and behaviour. E \& FN Spon; with the support of the Centre for Timber Technology and Construction at BRE

Farrell RW (2003) Structural features related to tree crotch strength. Doctoral dissertation, Virginia Polytechnic Institute and State University

Fengel D, Wegener G (eds) (1983) Wood: chemistry, ultrastructure, reactions. Walter de Gruyter, Berlin and New York, p 613

Garland H (1939) A microscopic study of coniferous wood in relation to its strength properties. Ann Mo Bot Gard 26(1):1-94

Gartner BL (1991a) Is the climbing habit of poison oak ecotypic?. Functl Ecol 696-704

Gartner BL (1995) Patterns of xylem variation within a tree and their hydraulic and mechanical consequences. In: Gartner BL (ed) Plant stems; physiological and functional morphology, Academic Press, New York, 125-149

Gilman EF (2003) Branch-to-stem diameter ratio affects strength of attachment. J Arboric 29(5):291-294

Harris RW (1992) Arboriculture: integrated management of landscape trees, shrubs and vines (No. Ed. 2). Prentice Hall Int 674

Harris PJ (2006) Primary and secondary plant cell walls: a comparative overview. N Z J For Sci 36(1):36-53

Hauer RJ, Wang W, Dawson JO (1993) Ice storm damage to urban trees. J Arboric 19(4):187-193

James RN (1990) Evolution of silvicultural practice towards wide spacing and heavy thinning in New Zealand. In: James RN, Tarlton GL (eds) New approaches to spacing and thinning in plantation forestry. Proceedings of a IUFRO symposium held at the Forest Research Institute, Rotorua, New Zealand, 10-14 April, 1989 (FRI Bulletin 151; pp 13-20). Rotorua, New Zealand: IUFRO, Forest Research Institute, N.Z. Ministry of Forestry

James KR (2003) Dynamic loading of trees. J Arboric 29:165-171

James KR, Haritos N, Ades PK (2006) Mechanical stability of trees under dynamic loads. Am J Bot 93:1522-1530 
Jeronimidis G (1980) The fracture behaviour of wood and the relations between toughness and morphology. Proc R Soc Lond B Biol Sci 208:447-460

Jungnikl K, Goebbels J, Burgert I, Fratzl P (2009) The role of material properties for the mechanical adaptation at branch junctions. Trees 23(3):605-610

Kane BC (2007) Branch strength of Bradford pear (Pyrus calleryana var. 'Bradford'). Arboric Urban For 33:283-291

Kane B, Farrell R, Zedaker SM, Loferski JR, Smith DW (2008) Failure mode and prediction of the strength of branch attachments. Arboric Urban For 34(5):308-316

Lilly S, Sydnor TD (1995) Comparison of branch failure during static loading of silver and Norway maples. J Arboric 21:302-305

MacDaniels LH (1923) The apple-tree crotch. Bulletin 419. Cornell University Agricultural Experiment Station, Ithaca, $\mathrm{p} 22$

MacDaniels LH (1932) Factors affecting the breaking strength of apple tree crotches. Proc Am Soc Hortic Sci vol 29:44

Majano-Majano A, Hughes M, Fernandez-Cabo JL (2012) The fracture toughness and properties of thermally modified beech and ash at different moisture contents. Wood Sci Technol 46:5-21

Marki C, Niemz P, Mannes D (2005) Comparative studies on selected mechanical properties of yew and spruce (trans: German). Schweiz Z Forstwes 15:85-91

Matheny NP, Clark JR (1994) Evaluation of hazard trees in urban areas. 2nd edn. International Society of Arboriculture, Champaign

Mattheck C (1990) Engineering components grow like trees. Materialwiss Werkstofftech 21:143-168

Mattheck C, Breloer H (1994) The body language of trees: a handbook for failure analysis. H.M. Stationary Office, London, p 240

Mattheck C, Vorberg U (1991) The biomechanics of tree fork design. Botanica Acta 104:399-404

Miller VJ (1959) Crotch influence on strength and breaking point of apple tree branches. Proc Am Soc Hortic Sci 73:27-32

Mohammadi MS, Nairn JA (2014) Crack propagation and fracture toughness of solid balsa used for cores of sandwich composites. J Sandwich Struct Mater 16(1):22-41

Morgan J, Cannell MGR (1994) Shape of tree stems: a reexamination of the uniform stress hypothesis. Tree Physiol 14:49-62

Niklas KJ (1992) Plant biomechanics: an engineering approach to plant form and function. University of Chicago Press, Chicago, p 622

Ozden S, Ennos AR (2014) Understanding the function of rays and wood density on transverse fracture behaviour of green wood in three species. J Agric Sci Technol B 4:731-743

Özden S, Ennos R, Cattaneo MEGV (2016) Transverse fracture properties of green wood and the anatomy of six temperate tree species. Forestry 1-12

Panshin AJ, de Zeeuw C (1980) Textbook of wood technologystructure, identification, properties, and uses of the commercial woods of the United States and Canada. 4th edn. McGraw-Hill Book Co., New York, p 722

Pfisterer JA (2003) Towards a better understanding of tree failure: investigations into bending stresses of branch junctions and reiterates of European Filbert (Corylus avellana L.) as a model organism. In Second International Symposium on Plant Health in Urban Horticulture. Arno Bynda, Berlin

Reiterer A, Sinn G, Stanzl-Tschegg SE (2002a) Fracture characteristics of different wood species under mode I loading perpendicular to the grain. Mater Sci Eng A 332(1):29-36

Reiterer A, Burgert I, Sinn G, Tschegg SE (2002b) The radial reinforcement of the wood structure and its implication on mechanical and fracture mechanical properties-a comparison between two tree species. J Mater Sci 37(5):935-940

Ruth WA, Kelley VW (1932) A study of the framework of the apple tree and its relation to longevity. Bull (University of Illinois (Urbana-Champaign campus) Agric Exp Stn) 376

Shigo AL (1985) How tree branches are attached to trunks. Can J Bot 63(8):1391-1401

Shigo AL (1989) A new tree biology. Shigo and Trees, Associates 636

Singh A, Tang L, Dao M, Lu L, Suresh S (2011) Fracture toughness and fatigue crack growth characteristics of nanotwinned copper. Acta Mater 59:2437-2446

Sinha A, Nairn JA, Gupta R (2012) The effect of elevated temperature exposure on the fracture toughness of solid wood and structural wood composites. Wood Sci Technol 46:1127-1142

Slater D, Ennos AR (2013) Determining the mechanical properties of hazel forks by testing their component parts. Trees 27:1515-1524

Slater D, Ennos AR (2015) Interlocking wood grain patterns provide improved wood strength properties in forks of hazel (Corylus avellana L.). Arboric J Int J Urban For 37:21-32

Slater D, Bradley RS, Withers PJ, Ennos AR (2014) The anatomy and grain pattern in forks of hazel (Corylus avellana L.) and other tree species. Trees 28:1437-1448

Smiley ET (2003) Does included bark reduce the strength of codominant stems? J Arboric 29:104-106

Smith I, Vasic S (2003) Fracture behaviour of softwood. Mech Mater 35:803-815

Smith I, Landis E, Gong M (2003) Fracture and fatigue in wood. The Atrium, Southern Gate. Wiley, Chichester, p 242

Spatz HC, Bruechert F (2000) Basic biomechanics of self-supporting plants: wind loads and gravitational loads on a norway spruce tree. For Ecol Manage 135:33-44

Spatz HC, Theckes B (2013) Oscillation damping in trees. Plant Sci 207:66-71

Spatz HC, Bruchert F, Pfisterer J (2007) Multiple resonance damping or how do trees escape dangerously large oscillations? Am J Bot 94(10):1603-1611

Stanzl-Tschegg SE, Navi P (2009) Fracture behaviour of wood and its composites. A review COST Action E35 2004-2008: Wood machining-micromechanics and fracture. Holzforschung 63(2):139-149

Stanzl-Tschegg SE, Tan DM, Tschegg EK (1995) New splitting method for wood fracture characterization. Wood Sci Technol $29(1): 31-50$

Theckes B, de Langre E, Boutillon X (2011) Damping by branching: a bioinspiration from trees. Bioinspir Biomim (6):1-11

Vasic S, Stanzl-Tschegg S (2007) Experimental and numerical investigation of wood fracture mechanisms at different humidity levels. Holzforschung 61:367-374

Verner L (1955) Hormone relations in the growth and training of apple trees. Idaho Agric Exp Sta Res Bull 28

Wardrop AB (1951) Cell wall organization and the properties of the xylem I. Cell wall organization and the variation of breaking load in tension of the xylem in conifer stem. Aust J Sci Res B 4(4):391-417

Yoshihara H, Nobusue K (2007) Mode I and mode II fracture toughness of densified Sitka spruce fabricated in an airtight atmosphere with high-temperature steam. Holzforschung 62:82-85 